\title{
RODOLFO LENZ (1920) FRENTE A LA GRAMÁTICA DE LA LENGUA CASTELLANA (1847) DE ANDRÉS BELLO ${ }^{1}$ \\ RODOLFO LENZ (1920) AND ANDRÉS BELLO'S GRAMÁTICA DE LA LENGUA CASTELLANA (1847)
}

\author{
JOSÉ GÓMEZ ASENCIO \\ Universidad de Salamanca \\ gasencio@usal.es
}

DARÍO ROJAS

Universidad de Chile

darioroj@uchile.cl

\section{RESUMEN}

En este artículo se contrasta ciertos puntos de vista expresados por Rodolfo Lenz en La oración y sus partes (1920) con aquellos planteados por Andrés Bello en la Gramática de la lengua castellana destinada al uso de los americanos (1847), resaltando exclusivamente aquellos en que Lenz ofrece disonancias explícitas frente a las ideas bellistas. Encontramos tanto críticas explícitas como rechazos a teorías, a términos (conectados con divergencias doctrinales), o a asuntos descriptivos propios de Bello o sostenidos (también o especialmente) por Bello. Tales reproches, que en ocasiones degeneran en invectivas, con frecuencia se presentan bien argumentados, pero en otros casos son simplemente enunciados, como opiniones disconformes. Los posicionamientos de Lenz al margen o en contra de Bello tienen fuente en las propias concepciones teóricas, terminológicas, gramaticográficas o actitudinales del propio Lenz. Adicionalmente, contextualizamos la intervención de Lenz en el marco de su estrategia de construcción de una imagen pública, de posicionamiento y legitimación en el campo cultural chileno, en el cual encontró resistencias considerables y en el que, por tanto, prometía tener mayor resonancia el gesto polémico de situarse frente a Bello.

Palabras clave: Historiografía lingüística; gramática española; glotopolítica; historia de las ideas lingüísticas.

${ }^{1}$ Este artículo se enmarca en los proyectos I+D FFI2016-76874-P (Gobierno de España) y FONDECYT Regular 1150127 (CONICYT, Gobierno de Chile), y corresponde a una versión revisada de una comunicación conjunta presentada en el XI Congreso de la Sociedad Española de Historiografía Lingüística, celebrado en Buenos Aires, Argentina, del 19 al 21 de abril de 2017. 


\begin{abstract}
We contrast the points of view expressed by Rudolf Lenz in La oración y sus partes (1920) with those raised by Andrés Bello in the Gramática de la lengua castellana destinada al uso de los americanos (1847), highlighting those in which Lenz openly disagrees with Bello's ideas. We find both explicit criticisms and rejections of theories, terms (connected with doctrinal divergences), or Bello's own descriptive issues or sustained (also or especially) by Bello. Such reproaches, which sometimes degenerate into invective, often present themselves well argued, but in other cases they are simply enunciated, such as dissenting opinions. The positions of Lenz on the margin or against Bello have a source in Lenz's own theoretical, terminological, grammaticographic or attitudinal conceptions. Additionally, we contextualize Lenz's intervention within the framework of his strategy of constructing a public image, of positioning and legitimization in the Chilean cultural field, in which he found considerable resistance and in which, therefore, the gesture of opposing Bello had greater resonance.
\end{abstract}

Keywords: Linguistic historiography; Spanish grammar; glottopolitics; history of linguistic ideas.

Recibido: 17/01/2019. Aceptado: 11/06/2019.

\title{
1. INTRODUCCIÓN
}

$\mathrm{D}$ os de las gramáticas del español más potentes nunca escritas lo fueron por chilenos adoptivos. Se trata -y esto es bien conocido por los historiadores de la gramaticografía del español- de la Gramática de la lengua castellana destinada al uso de los americanos (1847), del venezolano Andrés Bello, y de La oración y sus partes (1920) del alemán Rudolf (o Rodolfo) Lenz ${ }^{2}$. Dos textos de primerísimo nivel. Dos obras de dos personajes complejos y superdotados sin duda; dos polígrafos de mente amplia y abierta, preocupados no solo por la gramática en sí-que también- cuanto por cuestiones sociales y educativas; dos intelectuales de altísimo prestigio y ciertamente influyentes en la sociedad, la universidad y la cultura chilenas (y no solo chilenas).

No parece necesario - de hecho, ni siquiera es conveniente- insistir aquí en las aportaciones teóricas o descriptivas de una y otra gramáticas, o en su importancia intrínseca o en tanto que producto cultural propio de los momentos históricos en que fueron concebidas y publicadas, o en su trascendencia e influencia posteriores, sea en el propio Chile, sea fuera de las fronteras de este país, en el universo (pan) hispánico. En ello se han ocupado ya muchos trabajos que el lector interesado po-

${ }^{2}$ Salvo que se indique lo contrario, en adelante se cita esta obra por la cuarta edición, publicada en Chile: Lenz (1944). 
drá consultar a su conveniencia; de ello se seguirán ocupando estudios venideros con seguridad útiles y novedosos.

El objetivo del presente trabajo es más específico: confrontar ambas gramáticas con el objetivo enfocado en las disonancias explícitas, en las discrepancias manifiestas que se presentan en la obra de 1920 con respecto a la de 1847 (ver apartados 3.1 a 3.3). No interesarán aquí: (i) ni las concomitancias entre ambos textos por causa de aquel componente de la tradición gramatical hispana que es compartido por los dos autores (sea, por ejemplo, la aceptación de la existencia de género neutro en español); (ii) ni las concordancias debidas a la aceptación por parte de Lenz de ideas propias de Bello (sea, por ejemplo, el caso de la denominación y la mayor parte de los valores de las formas verbales); (iii) ni las ideas o aportaciones -más o menos- originales que presenta cada cual y que le son privativas. Se analizarán tan solo aquellos casos en que Lenz se coloca manifiestamente al margen, enfrente o en contra de los puntos de vista sostenidos o defendidos por su predecesor, y se procurará sacar lección de ello. Adicionalmente, se ofrece una interpretación de por qué Lenz se enfrenta a Bello (ver apartado 3.4), necesaria de ofrecer si se entiende que la actividad gramaticográfica es, como toda actividad metalingüística, una intervención en última instancia (gloto)política.

\section{LENZ FRENTE A LA HEGEMONÍA BELLISTA}

Al menos en materia gramatical, escapar de Bello en Chile después de 1850, esquivar sus puntos de vista, eludirlo, no debió de ser tarea fácil. Oponerse a él, enfrentarse de modo palmario, ponerse en su contra, disentir en general debía de considerarse incluso asunto arriesgado, dado el poderío de la hegemonía bellista en la cultura y la educación (gramatical) chilenas.

La tremenda influencia y prestigio de la obra gramatical de Bello probablemente fue amplificada por el gigantesco prestigio de su figura política y por su rol como agente principal en la conformación de un campo cultural y político en el Chile independiente (Jaksić, 2010). Bello fue el "state-builder" más prominente del periodo 1831-1861, bajo la llamada República Conservadora. Tras su llegada a Chile en 1829, Bello protagonizó facetas tan relevantes como son la conformación del sistema educativo nacional, principalmente mediante la fundación de la Universidad de Chile (1842) de la que fue rector hasta su muerte (en 1865), y la promulgación del Código Civil chileno (1855), el que serviría luego de modelo para otras naciones hispanoamericanas a lo largo de todo el XIX, y que, en lo fundamental, sigue en vigencia hasta el día de hoy en Chile.

Es decir, contender con Bello en gramática durante todo ese siglo, y hasta bien entrado el siguiente, no era contender solo en gramática, y ni siquiera solo con Bello; podía interpretarse más bien como un enfrentamiento (si bien simbólico) 
con el Estado y con el orden que lo sostenía, en la medida en que Bello por metonimia era el Estado y la gramática del mismo modo era su orden. Un ejemplo aleccionador de lo anterior (Bustos, Valladares y Rojas, 2015) se encuentra en el ostracismo académico que sufrió José Ramón Saavedra (1821-1907), presbítero chileno autor de una Gramática elemental de la lengua española publicada en 1857 en Santiago (y reeditada dos años después) y de una Censura de la Gramática de la lengua castellana del señor don Andrés Bello, de 1862. Su objetivo era que su Gramática elemental fuera considerada "oficial” en la educación chilena, en sustitución de la obra de Bello, que Saavedra consideraba antipedagógica (un "extravío de la enseñanza") y errada además en cuestiones de fondo. Su propuesta fue dos veces rechazada por el Consejo de Instrucción Pública. Saavedra acusó que en el medio cultural chileno existía una "veneración supersticiosa" hacia Bello. Tuvo que contentarse con que el Estado diera aprobación oficial a su texto sobre enseñanza de la doctrina cristiana. Y mientras tanto -aunque no es seguro que esto lo haya contentado-, desde la década de 1850 proliferaron los compendios y versiones escolares de la Gramática de Bello, junto con las reimpresiones de la obra original (véase Velleman, 2002, para un panorama general de la recepción de la obra de Bello en Chile).

Lenz, llegado a Chile en 1890 (véase Escudero, 1963; Ennis, 2016; y Bernaschina, 2013) para formar parte del cuerpo de especialistas del recién creado Instituto Pedagógico, se enfrentó en el medio local con una importante resistencia a sus ideas cientificistas y descriptivistas, de lo que da cuenta por ejemplo el ácido cuestionamiento de Eduardo de la Barra hacia los profesores alemanes del Pedagógico (Velleman, 2007) o la reseña crítica del sacerdote Manuel Antonio Román a su Diccionario etimológico (Lenz, s.f.). Lenz, formado en la filología históricocomparada europea, la única lingüística considerada "científica" en esa época, introdujo una fractura radical en la manera de entender el estudio de las lenguas en Chile, que hasta entonces tenía un marcado tinte pedagógico-normativista, ciertamente inspirado en Bello (Rojas, 2017). Precisamente en la crítica de Román al diccionario de Lenz encontramos el contraste expresado de manera diáfana, al tiempo que el sacerdote chileno lo compara con Bello, con la intención de dejar mal al alemán, por supuesto:

Hasta ahora todos habíamos creido que la enseñanza de la gramática era para hablar y escribir correctamente, como la gente educada; pero ahora el Dr. Lenz nos dice que estábamos profundamente equivocados y que la gramática, por lo menos en Chile, es para hablar y escribir 'la lengua huasa'. [...] En fin, no queremos cansar al lector como nos cansó a nosotros la obra del Dr. Lenz, que ojalá no prosiga con ella, porque hace un verdadero y funestísimo mal al país [...]. Concrétese, cuanto más, a la fonética del castellano, que es su especialidad, pero no venga a echarnos a 
perder lo poco que nos queda de la lengua que tanto nos enseñó, corrigió y purificó el filólogo verdadero y consumado gramático don Andrés Bello. (cit. en Lenz, s.f.)

Entonces, como sujeto enfrentado a una tradición local con tanta personalidad bellista, Lenz no podía no sucumbir a tales y tantos encantos como se encuentran en la gramática de Bello, y -como casi todo el mundo- supo admirar su trabajo e inspirarse sobradamente en él:

En mi curso de gramática castellana he usado como libro fundamental la Gramática castellana de Andrés Bello, en la edición anotada por R. J. Cuervo. Esta obra es, sin duda, el compendio más completo ${ }^{3}$ y más concienzudo que existe respecto a la gramática moderna de la lengua española (Lenz, 1920: \$5).

Pero no todo acabó de parecerle bien; y se lee inmediatamente a continuación:

Sin embargo, creer que las teorías que Bello estableció en 1847 deben guardarse intactas en la enseñanza, es lo mismo que negar el progreso de la filología castellana desde aquella época hasta hoy. Esos profesores antiguos, que hasta ahora ni siquiera toman en cuenta las enmiendas y correcciones de Cuervo, considerarán como sacrilegio el que yo insista especialmente en aquellos puntos en que las teorías de BELLO me parecen de valor dudoso o enteramente inaceptables (Lenz, 1920: \$5).

Lenz aceptó el riesgo de ser considerado sacrílego y osó rebatir a Bello 73 años después de la publicación de la primera edición de la gramática de este. La disidencia no solo concernió a cuestiones relacionadas con la enseñanza de la gramática; o a asuntos de naturaleza filológica (en lo que esta tiene de análisis de textos, de historia del español o de gramática comparada, algo a lo que Bello ciertamente no llegó en su desarrollo pleno, o algo por lo que Bello no se interesó especialmente desde su concepción de la gramática como disciplina esencialmente sincrónica); o a la escasa incidencia o el desdén, incluso, de que habían sido objeto en Chile las anotaciones de Cuervo a Bello (muchas de ellas, como es sabido, a su vez de naturaleza filológico-historicista), que es lo que podría deducirse de las palabras arriba transcritas. La desavenencia afectó también a otros parámetros, de cuya categorización se tratará en lo que sigue.

\footnotetext{
${ }^{3}$ Tiene su interés que Bello (1847, Prólogo) dijese de la gramática de Salvá (1831) algo parecido a esto: "He mirado esta última como el depósito más copioso de los modos de decir castellanos; como un libro que ninguno de los que aspiran a hablar y escribir correctamente nuestra lengua nativa debe dispensarse de leer y consultar a menudo" (salvo que se indique lo contrario, todos los subrayados de este artículo son nuestros).
} 


\section{LAS CRÍTICAS DE LENZ A BELLO}

\subsection{Enmiendas de naturaleza teórica}

De ellas la mayor parte atañe a las definiciones bellistas de ciertas categorías verbales (para más detalles, véase Gómez Asencio, 2016). Conviene ahora destacar estas:

3.1.1. El parágrafo 7 de La oración y sus partes lleva este encabezado: Definiciones antiguas de las partes de la oración: Andrés Bello. Queda clara ahí la consideración que le merecía a Lenz la clasificación de Bello, quien en ese epígrafe pasa a formar grupo con gramáticos nada cercanos en el tiempo - ni en lo demás- como Dionisio Tracio o Sánchez de las Brozas. Sostiene Lenz ahí que Bello trató de definir las partes de la oración desde el punto de vista de su oficio pero que "sólo lo consiguió perfectamente en el verbo" "; se ha de inferir que fracasó con las otras clases de palabras.

3.1.2. Así, sostiene que "en el substantivo ya flaquea la definición [de Bello] por un "puede» que le parece inevitable al autor: "El substantivo es una palabra que puede servir para designar el sujeto de la proposición»" [Bello \$41]. A nuestro entender, la definición de Bello es clara y acertada: en efecto, puede viene ahí a significar 'es susceptible por sí solo' de ejercer ese oficio, algo que lo caracteriza, lo aísla y lo define. La crítica se entiende menos: (i) si se comprueba que Bello, inmediatamente después de lo transcrito, añade: "Se dice que puede servir, no que sirve, porque, además de esta función, el sustantivo ejerce otras" ${ }^{5}$; la de sujeto sería la prototípica, el rasgo caracterizador de entre otros que igualmente presenta; (ii) si se examina la definición que Lenz acaba ofreciendo: "substantivo es toda palabra que sirve de sujeto activo o pasivo de una proposición” (Lenz, 1920: \$72).

3.1.3. Tampoco se muestra precisamente generoso Lenz en su comentario respecto al adjetivo en Bello: "Bello se contenta con esta explicación: "Llámanse adjetivos porque suelen añadirse al substantivo». Respecto a su función, sólo dice que modifican al substantivo, se refieren a él y lo modifican directamente" (Lenz, 1920: \$7). No resulta fácil comprender a qué viene ese "se contenta" (de hecho, Bello no se contenta: dice más cosas) o ese "sólo" de la cita de Lenz: esa es la función del adjetivo, aquella con la que Bello ha decidido caracterizarlo y distinguirlo de las otras partes de la oración. No lejos, por lo demás, le anda la definición de adjetivo

\footnotetext{
${ }^{4}$ Algo, por otra parte, de lo que Bello era perfectamente consciente y que derivaba de la propia naturaleza de la clase verbo: este, frente a las demás categorías verbales, "ejerce una sola [función], de que ninguna otra palabra es susceptible" (Bello $\$ 41)$.

${ }^{5}$ Para las funciones del sustantivo en Lenz (coincidentes, como no podía ser de otro modo, con las de Bello), cfr. $\$ 49$.
} 
del propio Lenz: "toda palabra variable que modifica o determina a un substantivo [...]” (Lenz, 1920: \$138)

3.1.4. "En cuanto a la preposición, [Bello] da una explicación poco satisfactoria" (Lenz, 1920: \$7). No desvela, sin embargo, nuestro autor el motivo de su insatisfacción.

3.1.5. Tampoco convence a Lenz la definición bellista de palabra; de hecho la contrasta con la de la gramática académica: "Cada palabra es un signo que representa por sí solo alguna idea o pensamiento" (Bello, 1847: \$5); "Llámase palabra [...] la sílaba o conjunto de sílabas que tiene existencia independiente para expresar una idea" (GRAE, 1917: \$5); para concluir, con razón: "Bello es menos explícito" (Lenz, 1920: \$36); en efecto, faltaba lo de la existencia independiente.

\subsection{Desacuerdos terminológicos (que conectan con divergencias doctrinales)}

Desde bien pronto - desde el \$3- Lenz muestra preocupación por la cuestión terminológica y, en su propuesta de reforma de la gramática y su enseñanza, considera conveniente llevar a efecto una revisión de los términos técnicos de la disciplina (y claro queda que también de la realidad lingüística y conceptual que se esconde bajo ellos). Lo relevante a los efectos de este trabajo son los motivos, sobre todo el primero, que impulsan tal revisión: "Primero, porque debido a las innovaciones de Andrés Bello, no existe la uniformidad deseable en esta materia, y segundo, porque las definiciones de todas las gramáticas castellanas son muy imperfectas e insuficientes" (Lenz, 1920: \$3). Concentrar en Bello y achacarle (solo) a él y sus originalidades la carencia de uniformidad terminológica en materia de gramática es, cuando menos, hiperbólico; es, cuando más, injusto; es, en cualquier caso, desdeñoso con la tradición gramatical hispánica anterior y posterior.

Son numerosos los retoques que, por toda su obra, Lenz hace a las propuestas terminológicas originales de Bello. Entre ellos:

3.2.1. A propósito de atributo y predicado. Sin entrar en detalles, ahora irrelevantes, se podría afirmar que para Bello la oración es el conjunto de sujeto + atributo; esta segunda entidad o es presidida por el verbo o consiste estrictamente en un verbo (Bello, 1847: nota II). El predicado, por su parte, sería "una función del adjetivo, cuando refiriéndose al sustantivo [...] enuncia una cualidad del objeto

${ }^{6}$ Es más que probable que la crítica tenga que ver con el hecho de que Bello no explicita también que el adjetivo "determina", algo que -a juicio de Lenz- es crucial para delimitar la categoría adjetivo (véase Gómez Asencio, 2016). 
que este significa"; así las cosas, adjetivo sería la categoría y predicado, la función estipulada para ella.

Algo insufrible para Lenz, quien dedica el $\$ 9$ a Los términos «atributo» $y$ "predicado»: y enuncia: "Esta denominación fué, por desgracia, aceptada por Bello [...] y éste es un grave inconveniente de la terminología de Bello [...] Es necesario e imprescindible hacer cesar las ambigüedades y seguir, en oposición a la terminología de Bello, el uso antiguo de la lógica” (Lenz, 1920: \$9).

No parece fácil, sin embargo, mostrar acuerdo incondicional con Lenz a la luz de estas dos citas contrastadas:

El adjetivo predicado, constante en su referencia al sustantivo, puede hallarse en muy diversos lugares, ya construyéndose inmediatamente con el sustantivo (la oscura noche, el triste invierno), ya modificando al verbo (el día amaneció tempestuoso), ya designando el término de un complemento (se acreditan de valientes, tiene fama de hermosa, da en temerario). (Bello, 1847: nota II)

[Bello] aceptó el término sobrante predicado para designar al adjetivo precedido del verbo ser, es decir, para lo que antes se había llamado atributo. Con este procedimiento ya no era posible denominar convenientemente al adjetivo que acompaña al substantivo. (Lenz, 1920: \$9)

Lo cierto es que la lectura de Bello no sugiere la interpretación que hace Lenz: en Bello el término predicado no designa estrictamente al adjetivo precedido por el verbo ser, sino, en la práctica, a todo adjetivo referido a un sustantivo en cualquier combinatoria (los ejemplos que se ponen a continuación son todos de Bello y contienen todos adjetivos predicados ${ }^{7}$ ):

Es $\underline{\text { bueno, }}$ es $\underline{\text { malo }}$

Está ciego, está sordo

Nació enfermo, murió pobre, duerme tranquilo, corre apresurado, anda triste, se muestra esforzado

La oscura noche, el triste invierno

El día amaneció tempestuoso

Se acreditan de valientes, tiene fama de hermosa, da en temerario

3.2.2. A propósito de verbo perfectivolimperfectivo vs desinente/permanente. Llama Bello (1847: \$625) desinentes ${ }^{8}$ a los verbos (modernamente, predicados) puntua-

${ }^{7}$ El sintagma "adjetivo predicado" en Bello, quien añade: "Podrán preferirse otros términos para distinguir las dos cosas que yo llamo predicado y atributo; pero la distinción entre ambas es un hecho incontestable de la lengua".

${ }^{8}$ Salvo error en el cómputo, aparece tres veces en la obra de Bello. 
les, télicos o delimitados (arrancar, lanzar, caerse), esto es, a aquellos cuyo enunciado implica su terminación (frente a los durativos: nevar, leer); en sus propias palabras:

En unos verbos el atributo, por el hecho de haber llegado a su perfección, expira, y en otros, sin embargo, subsiste durando: a los primeros llamo desinentes, y a los segundos permanentes. Nacer, morir, son verbos desinentes, porque luego que uno nace o muere, deja de nacer o de morir; pero ser, ver, oir, son verbos permanentes, porque sin embargo de que la existencia, la visión o la audición sea desde el principio perfecta, puede seguir durando gran tiempo (Bello, 1847: \$625).

Para designar esa realidad lingüística, Lenz prefiere los términos perfectivo/imperfectivo. No se explicitan argumentos a favor ni en contra de ninguna de las dos opciones; mera preferencia.

\subsubsection{A propósito de frase adverbial vs complemento. Por frase adverbial en Lenz} parece que debamos entender lo que hoy se llama «sintagma preposicional» (grupo de preposición + sustantivo o equivalente); los elementos subrayados en puente de hierro, copa para vino (Lenz, 1920: \$89), mi salida de Barcelona se efectuó por la mañana, la escritura con máquina, escribo con máquina (Lenz, 1920: \$139), a la salida del sol (Lenz, 1920: \$263), por enfermedad, por estar enfermo (Lenz, 1920: $\$ 343)$, etc. son frases adverbiales.

Es bastante común que las menciones a frase adverbial por parte de Lenz vayan acompañadas de esta aclaración (sinonímica): "complemento ordinario en Bello". Lo cierto es que no se encuentra tal sintagma en la gramática de Bello, lo que ha de llevar a considerar que el sinónimo en este autor es, meramente, complemento (Bello, 1847: $\$ \$ 65-69)^{9}$. Tampoco en este caso apunta Lenz las razones de su preferencia terminológica.

3.2.4. A propósito de conjunción vs conjunción coordinante. Este asunto sobrepasa ampliamente la faceta terminológica. Es sabido que para Bello solo son conjunciones las que enlazan elementos análogos y equifuncionales ${ }^{10}$; así las cosas, se comprende bien la elección de Lenz, en cuyo sistema se contemplan dos tipos de

${ }^{9}$ Bello (1847: \$83) reserva el término técnico frase adverbial para los ahora llamados sintagmas adverbiales, esto es, grupos cuyo núcleo está configurado por un adverbio el cual es modificado por un complemento: lejos de todo trato humano.

10 "La conjunción sirve para ligar dos o más palabras o frases análogas, que ocupan un mismo lugar en el razonamiento" (dos sujetos de un mismo verbo, dos adjetivos de un mismo sustantivo, dos adverbios de un mismo adjetivo, dos complementos de una misma palabra, etc.) (Bello, 1847: $\$ 74)$. No existen en este sistema conjunciones subordinantes; de la subordinación se encargan otros elementos (por ejemplo, lo que Bello llama adverbios relativos (donde, cuando, mientras, porque, si, aunque, etc.). 
conjunciones: de coordinación y de subordinación: "Bello restringe el nombre de la conjunción a las coordinantes y llama las demás [...] «adverbios relativos». No me parece recomendable esta terminología” (Lenz, 1920: $\$ 140$, nota 1; explicaciones, redundantes aquí, en Lenz, 1920: \$336).

3.2.5. A propósito de artículo definido vs pronombre personal de tercera persona. También esto trasciende, y con mucho, la pura terminología, y es indicio de posicionamientos teóricos diferentes y distantes (cuyo tratamiento detallado se elude en este trabajo). Afecta a las formas él, ella, ello, le, la, lo, etc., que la tradición hispánica en general -con Lenz inmerso en ella- consideró formas del pronombre personal de tercera persona en paradigma con $y o$, tú (y variantes formales), mientras que Bello -y algún que otro gramático- estimó que no eran sino las formas plenas o tónicas o sustantivadas del llamado artículo definido, dando lugar junto con los demostrativos a este paradigma (Bello, 1847: $\$ \$ 273$ y ss.) con sus respectivas variantes de género y número: él / el; éste / este; ése / ese; aquél / aquel.

3.2.6. A propósito de las denominaciones de los tiempos verbales. Aquí Lenz plantea el irresoluto problema de cómo nombrar las diferentes formas temporales del verbo y se deshace en elogios a Bello, cuya terminología a este respecto le parece por lo general conveniente y apropiada (al menos para los valores primarios o matrices de cada forma): "sin duda el autor que más ha contribuido a adelantar nuestros conocimientos en la difícil materia de los tiempos de la conjugación castellana” (Lenz, 1920: \$287).

Y aquí Lenz se adelanta a todos en su perspicuidad: "Para evitar ambigüedades, en caso de duda usaré simplemente la forma latina o castellana del verbo modelo cantare, cantar (o dicere, decir), como denominación de los "tiempos»" (Lenz, 1920: \$287). El término técnico de cada tiempo es la propia forma o mención del tiempo en cuestión.

\subsection{Rectificaciones de carácter descriptivo}

Se incluyen en este apartado tanto los puros fenómenos descritos, su presentación, como el análisis lingüístico -anclado, por lo tanto, en una teoría gramatical concebida para dar cuenta de la lengua española- de dichos fenómenos, es decir, su interpretación metagramatical.

3.3.1. Sin pretensiones de exhaustividad, se cuentan dentro del primer tipo los siguientes fenómenos:

3.3.1.1. A propósito de ciertos usos de la voz pasiva. Lenz, con razón, sostiene que 
no se usa la voz pasiva de los verbos perfectivos (supra 3.2.2) o delimitados ni en presente ni en imperfecto cuando se trata de expresar la acción momentánea: "no se puede decir El niño es lavado por su madre, La casa era construida por un amigo" (Lenz, 1920: \$229): "la frase activa yo edifico una casa no se puede dar en pasiva, una casa es edificada por mí, porque de hecho no se dice asi”" (Lenz, 1920: \$57). La cuestión aquí radica en que Bello (Lenz, 1920: \$429) se vale justamente de este último ejemplo, "evidentemente por una inadvertencia” (Lenz, 1920: \$57).

3.3.1.2. A propósito del género. Escribe Lenz (1920: \$71): “el género gramatical de los substantivos que no terminan en $-o$, $-a$, es prácticamente dudoso y se determina por el uso; no vale la pena de molestar a los niños con reglas como las que da Bello en los párrafos 168 a 187”. Al argumento descriptivo se añade el pedagógico; en efecto, Bello, al modo de Villalón (1558) o de la gramática académica a partir de la cuarta edición (1796) (Gómez Asencio, 2011: 68-71), y tal vez por influencia de esta, incorpora tediosas reglas y excepciones, y largas listas de entradas léxico-gramaticales que a Lenz le parecen inútiles cuando no contraproducentes.

3.3.1.3. A propósito de la colocación del adjetivo. De nuevo Lenz recurre al argumento pedagógico: la fórmula de Bello ${ }^{11}$ "no resulta bastante explícita" y "he visto, en innumerables exámenes de castellano, que los niños no saben qué hacer con esta explicación, porque los mismos profesores no encuentran ejemplos adecuados que añadir a las «mansas ovejas» del autor" (Lenz, 1920: \$115), con su toque de ironía fresca a colación del ejemplo bellista. Por su parte, Lenz sugiere (1920: $\$ 116$; casi tres páginas) lo que entiende una explicación del fenómeno a partir de este recurso: adjetivo antepuesto, valor subjetivo, apreciación afectiva; adjetivo pospuesto, valor objetivo, especificación lógica.

3.3.1.4. A propósito de ciertos usos del gerundio. Lenz recuerda la "violenta crítica” con que Bello condena ciertos usos del gerundio (Bello, 1847: \$446) y, aunque no muestra un desacuerdo fuerte con esa posición, sí que pone de manifiesto una mayor laxitud, comprensión, adaptabilidad a los tiempos y tolerancia al menos pero no solo- con los gerundios de posterioridad: "Frases como «El general X llegó ayer a la capital, siendo recibido con grandes ovaciones populares» se leen constantemente en los diarios americanos (a menudo como traducción de cablegramas llegados en inglés), y no chocan a la mayoría de los lectores” (Lenz, 1920: \$251).

3.3.1.5. A propósito de las formas $-R A$ del indicativo. Esa misma actitud flexible y tolerante con los usos reales vuelve a encontrarse cuando le llega la hora a la

11 "El adjetivo antepuesto desenvuelve, explica; el pospuesto, particulariza, especifica" (Lenz, 1920: $\$ 115$ a propósito de Bello, 1847: \$47). 
forma cantara empleada con valor de 'había cantado' (y a veces también de 'cantó' o de 'cantaba', añade). La mera cita, algo larga, habla del espíritu independiente y reflexivo de Lenz, y será suficiente:

No sé si es realmente un arcaísmo, como dice BeLLo, $\$ 720$, y continúa «que debe evitarse, porque tiende a producir confusión»; la crítica, «cantara tiene ya en (el) lenguaje moderno demasiadas acepciones para que se le añada otra más», no me parece bien fundada [...] Una mera especulación teórica del profesor de gramática, según mi opinión, no es nunca razón suficiente para criticar un giro de lenguaje que efectivamente se usa [...]. El otro ejemplo está tomado de la crónica de un diario: «El señor $\mathrm{N}$. ha sido curado de las heridas que recibiera en un accidente automovilístico que le ocurrió hace poco». ¿¿Se tratará aquí también de un arcaísmo rebuscado, o de una manera de escribir corriente al autor? ¡Que lo decidan los profesores de estilo!

En todo caso, este uso, criticable o no, corrobora que el castellano moderno siente todavía el valor de indicativo de la forma en $-r a($ Lenz, 1920: \$290).

3.3.1.6. Para la consideración de ÉL, ELLA (artículo/pronombre) etc. supra 3.2.5.

3.3.1.7. Para la reflexión acerca de la conjunción supra 3.2.4.

3.3.2. Igualmente, las entradas que siguen sirven como muestras de las discrepancias entre ambos autores en relación con el tratamiento teórico-descriptivo -analítico e interpretativo, pues- de ciertos fenómenos gramaticales.

3.3.2.1. A propósito del estatus de mínimo, ínfimo y otros. Bello (1847: \$1026) escribe: "Minimo, infimo, que se usan como superlativos absolutos en una cosa minima, un precio infimo, son superlativos de régimen en «el minimo de los seres», «la ínfima de las clases»". Lenz (1920: \$124) les niega la condición de superlativos (en español actual, aunque lo fuesen en latín), para atribuirles la de puros adjetivos positivos. E insiste: "Construcciones como el mínimo de los seres, la infima de las clases, citadas por BELLO, son groseros latinismos".

3.3.2.2. A propósito del género de los infinitivos verbales. Es Bello (1847: \$294) de la opinión de que los infinitivos son sustantivos de género neutro; el argumento es que se reproducen por medio del pronombre neutro: estábamos determinados a partir, pero hubo dificultades en ello, y tuvimos que diferirlo. "Es un error", sentencia Lenz (1920: $\$ \$ 61$ nota y $81^{12}$ ): "se reproducen por neutros, en castellano, sólo los

${ }^{12}$ El $\$ 81$ lleva este título: Crítica de algunas teorías de ANDRÉS BELLO. Comienza así: "Conviene rectificar dos errores evidentes de Bello, que suelen enseñarse en Chile, en todas las clases de gramá- 
conjuntos de objetos o de ideas" y un infinitivo es como una proposición completa (sujeto con predicado).

3.3.2.3. A propósito de EL QUE, LA QUE, LOS QUE, LAS QUE, LO QUE. Es sabido que en la teoría bellista (Bello, 1847: $\$ \$ 323$ y ss.) tales expresiones ocultan dos realidades gramaticales diferentes:

(i) compuestas de dos palabras distintas:

los que no moderan sus pasiones son arrastrados a lamentables precipicios

(ii) equivalentes a una sola palabra:

la relación de las aventuras de don Quijote, en la que los lectores solo ven un entretenimiento...

Aquí interesa el primer caso. Según Bello, ahí el artículo está sustantivado, se prefiere la forma abreviada los a la íntegra ellos, y los sirve de antecedente al relativo, de modo que el artículo pertenece a una proposición y el relativo a otra; más o menos: Los/ellos [que no moderan sus pasiones] son arrastrados a lamentables precipicios. Lenz disiente rotundamente: "no se puede admitir el análisis" de Bello; y añade:

El artículo delante de un tal que especificativo, no modifica o, más bien, no determina a que, sino a toda la proposición relativa. No puedo, de consiguiente, aceptar la interpretación de BELLO (\$324), quien dice que el artículo en tal caso está substantivado. El artículo relativo, como palabra forzosamente átona, no es susceptible de substantivación alguna (Lenz, 1920: \$\$79 y 82-87).

Lo que se ha sustantivado, sigue Lenz, no es el que, sino toda la proposición relativa; el mismo fenómeno, pues, tiene lugar en $i$. que en $i$. de aquí abajo:
i. los que no moderan sus pasiones son arrastrados...
ii. los inmoderados en sus pasiones son arrastrados...

3.3.2.4. A propósito de QUE, conjunción completiva. Tampoco en esto está conforme Lenz con las ideas ciertamente novedosas de Bello (1847: \$\$316-319). Este parte de la idea de que este "que anunciativo" no es conjunción ${ }^{13}$, sino sustantivo neutro demostrativo -como esto- perteneciente a la proposición subordinante; así:

\section{i. que la tierra se mueve alrededor del sol es cosa averiguada}

\footnotetext{
tica castellana” (Lenz, 1920: \$81). Nueva incidencia pedagógica.

${ }^{13}$ De hecho, no podría serlo en su teoría, en la cual las conjunciones, todas, son palabras coordinantes, jamás subordinantes (supra 3.2.4).
} 


\section{ii. esto, la tierra se mueve alrededor del sol, es cosa averiguada}

Proposición subordinante: que es una cosa averiguada (y que es el sujeto de esa proposición)

Proposición subordinada: la tierra se mueve alrededor del sol

La teoría "es absolutamente inaceptable, y de hecho no ha sido aceptada por ningún otro filólogo" (Lenz, 1920: \$\$80, 260 y 344).

3.3.2.5. A propósito del participio invariable en $-D O$ en las formas compuestas del verbo. Los "participios" en $-D O$ de las formas verbales compuestas del español son tan peculiares que obligaron a Nebrija (1492) a idear una categoría nueva, nunca vista: el nombre participial infinito. Tales formas son como un participio, parecen un participio pasado (participial); significan sustancia y no tienen tiempos (nombre); y carecen de flexión (infinito). Lo cierto es que esta propuesta novedosa y reflexiva de Nebrija tuvo poco éxito en la tradición posterior.

Bello (1847: $\$ \$ 432-441)$ redescubrió esta doble faceta de las formas en $-D O$, y sentenció que hay dos participios: uno adjetivo (el que tiene flexión de género y número) y otro sustantivo o, mejor, sustantivado (vid. su Nota X) ("el que se emplea con el verbo haber"; "el participio se sustantiva cuando se construye con el verbo haber").

No es Lenz (1920: $\$ \$ 252-254$ ) partidario de tal propuesta; el participio es para él un adjetivo, y replica: "En cuanto a la función del participio invariable en he visto, es inadmisible la interpretación de BELLo de que el participio sea substantivado. De acuerdo con Cuervo, creo que se debe decir que en tal caso el participio se ha neutralizado, o adverbializado, o simplemente que se ha hecho invariable, porque ha perdido su función de adjetivo" (Lenz, 1920: \$253). La cuestión es que, nuevamente, su réplica viene sin argumentos: no se explica por qué "es inadmisible la interpretación de Bello", ni en qué se asienta su "creo que..."14; tampoco por qué si el participio es un adjetivo, el de he visto puede ser participio cuando de hecho "ha perdido su función de adjetivo".

3.3.2.6. A propósito de los modos verbales. Para ambos gramáticos los modos son formas del verbo. La disensión se produce al tratar de explicar su naturaleza y la causa genérica de sus usos concretos: según Bello, obedecen estos a razones sobre todo sintáctico-formales; según Lenz, a motivaciones semánticas. Difícil el acuerdo en esto; casi imposible mayor distancia: control combinatorio vs control significativo e intencional:

${ }^{14}$ Más allá del criterio de autoridad: lo dice Cuervo. En efecto, en su nota 71, al final, se lee: "No parece acertado calificar de sustantivo o de sustantivado al participio de he escrito; bastaría indicar el hecho llamándole invariable". Tampoco queda claro qué se quiere decir con "adverbializado" (salvo, tal vez, su carácter no flexivo), ni qué ventajas reporta "adverbializado" frente a "sustantivado". Etc. 
Llámanse MODOs las inflexiones del verbo en cuanto provienen de la influencia o régimen de una palabra o frase a que esté o pueda estar subordinado. (Bello, 1847: $\$ 450)$

Modo es la categoría gramatical según la cual se clasifican las formas verbales propiamente tales [...] subjetivamente (desde el punto de vista del que habla) en correspondencia con su valor lógico. (Lenz, 1920: \$285)

Todo legítimo; opiniones divergentes con todo derecho y razón; nada que destacar, salvo esta crítica explícita ¡y necesaria?: "tampoco son felices las [definiciones] que da Bello (1847: $\$ 448$ y sigts.), porque parte de la base de que las formas verbales estén o puedan estar dependientes de ciertos verbos dominantes" (Lenz, 1920: \$285). Ahora bien: esta no parece ser la causa de la infelicidad de la definición bellista, la cual más bien parece emanar del punto de partida a priori y no internamente justificado de Lenz y según el cual los modos verbales son entidades de carácter semántico; y eso es, precisamente, lo que habría que haber dejado demostrado.

\subsection{Discrepancias actitudinales y atingentes a lo normativo}

Ambos personajes llevaron a cabo su actividad de descripción y análisis gramaticales y desempeñaron su labor gramaticográfica en un contexto cultural y educativo chileno; también en un espacio geográfico y social chileno, todo lo cual, sin duda, hubo de condicionarlos. A pesar de la distancia temporal que existe entre uno y otro gramático, ambos actúan en el marco del proceso político de la formación del Estado-nación; sus intervenciones, en consecuencia, se prestan a lecturas desde un enfoque glotopolítico (Del Valle, 2017), que, al destacar los condicionantes políticos, culturales e ideológicos del conocimiento especializado, se inscriban en lo que Valdez (2015: 87) llama historiografía crítica de la lingüistica.

Bello interviene en la etapa inicial y de consolidación de las estructuras fundamentales de la nación chilena; Lenz, en el momento de modernización nacional de fines del siglo XIX y comienzos del XX. Pero el marco común es suficientemente flexible como para también permitir entender sus diferencias de actitud. Para Bello, si la gramática es “teoría particular” del idioma, la gramaticografía y el análisis gramatical los concibe como actividad aplicada, orientada a que los usuarios de la lengua dominen "el arte de hablarla correctamente". Luego, la gramaticografía para él es un género de las "escrituras disciplinarias", como ha destacado Velleman (2014), es decir, una acción de planificación lingüística y social, que se sentía muy necesaria en el contexto histórico en que ocurría. El objetivo de producir y preservar la unidad del idioma al alfabetizar a la población conlleva una actitud negativa 
hacia lo dialectal, hacia lo que amenaza esta unidad. En el caso chileno, el enemigo de Bello fue el dialecto vernáculo de las clases bajas, una fuerza centrífuga respecto del modelo culto y literario que para Bello debía servir de norma y de garante de la unidad (Moré, 2014; Gómez Asencio, 2001).

Para Lenz, en cambio, formado ya en una "lingüística científica" moderna, el objetivo de la gramaticografía y del estudio de la lengua es otro muy distinto. Lenz, en las varias polémicas en que intervino, destacaba la separación limpia entre "ciencia" y "arte", idea que para el campo cultural chileno constituía una fractura paradigmática, pero que era completamente coherente, por un lado, con el cientificismo positivista vigente en la época y, por otro lado, era funcional para el proyecto estatal de modernizar la educación y la actividad cultural en Chile, modernidad que pasaba en parte precisamente por la aceptación de los presupuestos del positivismo científico.

Para Lenz, el foco del gramático debía estar en entender cómo es la lengua efectivamente (a pesar de que no desconocía la necesidad de enseñar también una norma culta: lo que quería evitar es la reducción de la lengua a la norma [véase Soto, 2016]). Recuérdese que los neogramáticos, en quienes en buena medida se inspiraba, habían destacado la necesidad de acudir a los dialectos vivos, a la lengua oral popular, como lugar de manifestación auténtica de los procesos de cambio. Esta era para Lenz la justificación principal de estudiar el lenguaje del pueblo ("La mala pronunciacion del último patan puede tener para la lingüística el mismo interes que un cultivo de bacilos de la peste bubónica para la biolojía i la medicina", explicaba con una comparación reveladora; Lenz, s.f.), y por lo mismo tampoco le interesaba censurarlo. No existe en él el interés por intervenir, por emprender acciones de planificación lingüística sobre el lenguaje popular. Por otra parte, debe aclararse que su "rescate" del habla del pueblo no tenía que ver tanto con un proyecto político de valorizar lo popular como elemento definitorio de la nación; no era un romántico. Su propuesta tenía que ver, más bien, con fundamentar su actividad en el prestigio de una "ciencia moderna" y de su actitud descriptivista y objetiva.

Lenz, entonces, al irrumpir en el campo cultural chileno e introducir una fractura tan radical en la manera de entender el estudio del lenguaje y la gramaticografía, se vio forzado a construir su imagen pública, a fundamentar su autoridad, de manera polémica respecto de la principal fuente de autoridad del paradigma anterior: Bello. Quizá por lo mismo, Lenz lleva la discusión con Bello al terreno en que este último era considerado un maestro: la descripción gramatical, y no de las variantes dialectales populares (objeto preferido de reflexión de Lenz), sino de la lengua culta (objeto preferido de Bello). Da la impresión de que Lenz quiso mostrarse superior a Bello "jugando de visita", lo cual habría hecho más fulminante el derrumbe de la autoridad del gramático chileno-venezolano. Para Lenz quizá era muy fácil (y por lo mismo poco efectivo, en su fin de autolegitimación) refutar a 
Bello en asuntos como si tales o cuales variantes eran o no correctas, porque muy probablemente para el alemán estos eran más bien seudoproblemas.

En suma, las actitudes de uno y de otro acerca de la norma, de lo correcto e incorrecto y -lo que es más importante- acerca de las variedades chilenas del español / las variedades del español hablado/-as en Chile, sus abordajes respectivos en torno a esos asuntos fueron, pues, ciertamente muy diferentes. Los fenómenos recogidos y anotados, así como el carácter de las propias anotaciones, fueron tales y tantos, de tal riqueza y enjundia que no es posible ocuparse de ellos en esta ocasión.

\section{CONCLUSIONES}

En el presente trabajo se ha puesto el foco analítico en las discrepancias que Lenz manifiesta respecto de la Gramática de Bello en su obra La oración y sus partes y se ha contextualizado la intervención de Lenz, entendida como una intervención glotopolítica (es decir, cuyas motivaciones manifiestan lo político del lenguaje y de la actividad metalingüística), poniéndola en el marco de su estrategia de posicionamiento y legitimación en el campo cultural chileno, en el cual encontró resistencias considerables (por algo Lenz escoge precisamente al gigante Bello como interlocutor/contendor). Se han encontrado críticas explícitas tanto como rechazos a teorías, términos y asuntos descriptivos propios de Bello o sostenidos (también o especialmente) por Bello. Tales reproches, que en ocasiones degeneran en invectivas, con frecuencia se presentan bien argumentados, pero en otros casos son simplemente enunciados, como opiniones disconformes.

En resumen, Lenz ofrece enmiendas de naturaleza teórica (definición de las partes de la oración y del concepto de palabra), muestra desacuerdos terminológicos (sobre las distinciones atributo/predicado, perfectivo/imperfectivo, desinente/permanente, frase adverbiallcomplemento, conjunción/conjunción coordinante, artículo definido/pronombre personal de 3. a persona y los nombres de los tiempos verbales) y hace rectificaciones descriptivas (sobre usos de la voz pasiva, el género, la colocación del adjetivo, algunos usos del gerundio, las formas -ra del indicativo, éllella y la conjunción, junto con otros detalles). Todo este conjunto de críticas minuciosas (que quedaron explicadas entre los apartados 3.1 y 3.3) pueden cobrar un sentido más claro si se las entiende como parte de un desacuerdo más profundo de Lenz con Bello, que tiene que ver con sus distintas actitudes acerca de lo normativo (3.4), que en última instancia es una discrepancia de tipo ideológico y político.

Si hubiese que sacar lección de lo antedicho, en ella habría que dejar destacadas ideas como las que siguen: la extraordinaria formación lingüística de Lenz, su espíritu independiente y prácticamente indomeñable, su valentía personal al ponerse enfrente -cuando no en contra- del maestro chileno por excelencia, Bello, o su 
rigor científico. También su capacidad crítica, analítica y reflexiva; o su rechazo implícito del principio de autoridad, así como de la copia irreflexiva de las ideas o bien convencionales en la tradición gramatical hispánica, o bien egregias de autores consagrados: casi todo es sometido a revisión. Igualmente, la racionalidad de su aproximación a la lengua española, su sentido y sensibilidad lingüísticos, su minuciosidad descriptiva y su tino en la reflexión y el análisis gramaticales, cualidades todas especialmente meritorias si se repara en que el español no era su lengua materna y fue, pues, para él lengua aprendida y no adquirida.

A pesar de lo que el propio Lenz dejó anunciado (1920: $\$ 5$; supra 2.), las mejoras provenientes de la Filología, esto es, las reformas llevadas a cabo sobre las propuestas de Bello a partir del "progreso de la filología castellana desde aquella época hasta hoy" (=1920) son prácticamente inexistentes. Por eso no se han comentado en este trabajo: lo que Lenz aprovechó de la filología o de la gramática histórica o comparada no lo usó, en lo sustancial al menos, contra Bello, y apenas si ha podido ser considerado en este estudio. Muy probablemente haya que interpretar la alusión al "progreso" de la disciplina más bien como un ejercicio retórico que forma parte de su estrategia de autolegitimación en el contexto de modernización de la nación.

Los posicionamientos al margen o en contra de Bello tienen otra fuente: la propia concepción teórica gramatical de Lenz (bien influenciada, como es sabido y el propio autor declara, por el psicologismo de Wundt), sus preferencias terminológicas, sus puntos de vista acerca de la descripción de la lengua española, o su actitud ante las normas, ante el "hablar bien".

\section{REFERENCIAS}

Bello, Andrés. (1847). Gramática de la lengua castellana. Con Notas de Rufino J. Cuervo (1881). Edición completa, esmeradamente revisada; corregida y aumentada con un prólogo y frecuentes observaciones de Niceto Alcalá-Zamora y Torres (1945). Buenos Aires: Editorial Sopena Argentina.

Bello, Andrés. (1847). Gramática de la lengua castellana destinada al uso de los americanos. Edición crítica de Ramón Trujillo [1981]. Santa Cruz de Tenerife: Instituto Universitario de Lingüística Andrés Bello. Cabildo Insular de Tenerife.

Bernaschina, Vicente. (2013). Rodolfo Lenz, 150 años en disputa con el imperio de la Lengua. Universum, 28(2), 117-138.

Bustos, Tamara, Juan Carlos Valladares y Darío Rojas. (2015). José Ramón Saavedra y Adolfo Valderrama: lengua y educación en el Chile del siglo XIX. Universum, 30(1), 39-53.

Del Valle, José. (2017). La perspectiva glotopolítica y la normatividad. Anuario de Glotopolitica, 1, 17-39. 
Ennis, Juan Antonio. (2016). Rodolfo Lenz: economías de la lengua y políticas de la lingüística. Boletín de Filología, 51(1), 117-145.

Escudero, Alfonso M. (1963). Rodolfo Lenz. Thesaurus, 18(2), 445-484.

Gómez Asencio, José J. (2001). Gramática para americanos, gramática para todos. Comunicación presentada en II Congreso Internacional de la Lengua Española, Valladolid, en línea: http://congresosdelalengua.es/valladolid/ponencias/ unidad_diversidad_del_espanol/2_el_espanol_de_america/gomez_j.htm

Gómez Asencio, José J. (2011). Los principios de las gramáticas académicas (17711962). Bern: Peter Lang.

Gómez Asencio, José J. (2016). Categorías en La oración y sus partes (1920) de Rodolfo Lenz: Clases. Boletín de Filología, 51(1), 147-185.

Jaksić, Iván. (2010). Andrés Bello: la pasión por el orden. 2. ${ }^{a}$ ed. Santiago: Editorial Universitaria.

Lenz, Rodolfo. s.f. Anexo segundo al Diccionario etimológico. Edición no venal del autor.

Lenz, Rodolfo. (1920). La oración y sus partes, Madrid: Publicaciones de la Revista de Filología Española.

Lenz, Rodolfo. (1925). La oración y sus partes. Estudios de gramática general y castellana. 2a ed. Madrid: Publicaciones de la Revista de Filología Española.

Lenz, Rodolfo. (1935). La oración y sus partes. Estudios de gramática general y castellana. $3^{\mathrm{a}}$ ed. Madrid: Publicaciones de la Revista de Filología Española.

Lenz, Rodolfo. (1944). La oración y sus partes. Estudios de gramática general y castellana. $4^{\mathrm{a}}$ ed. Santiago de Chile: Editorial Nascimento. [Al cuidado del P. Alfonso M. Escudero].

Moré, Belford. (2014). Lengua y poder en la obra gramatical de Andrés Bello. Caracas: Fundación Casa Nacional de las Letras Andrés Bello.

Nebrija, Antonio de. (1492). Gramática sobre la lengua castellana. Edición, introducción y notas de Miguel Á. Esparza y Ramón Sarmiento [1992]. Madrid: SGEL.

Real Academia Española. (1796). Gramática de la lengua castellana. 4a ed. Madrid: Por la viuda de don Joaquin Ibarra.

Rojas, Darío. (2017). Representaciones del cambio lingüístico en Chile durante el siglo XIX: “¿progreso o decadencia?”. Literatura y Lingüistica, 36, 243-262.

Soto, Guillermo. (2016). Rodolfo Lenz y la enseñanza del castellano como idioma patrio en Chile. Boletín de Filología, 51(1), 211-238.

Valdez, Juan R. (2015). En busca de la identidad. La obra de Pedro Henríquez Urena. Buenos Aires: Katatay Ediciones.

Velleman, Barry L. (2002). La recepción de las ideas lingüísticas de Bello en Chile. En Miguel Á. Esparza Torres, Benigno Fernández Salgado y Hans-Josef Niederehe (eds.), Actas del III Congreso Internacional de la Sociedad Española de Historiografía Lingüistica, 721-732. Madrid: Arco/Libros. 
Velleman, Barry L. (2007). Las ideas lingüísticas y pedagógicas de Eduardo de la Barra y su polémica con Lenz y Hanssen. Contextos, 18, 179-193.

Velleman, Barry L. (2014). Bello y las "escrituras disciplinarias": diccionarios, gramáticas, ortografías. Boletín de Filología 49(1), 179-192.

Villalón, Ldo. (1558). Gramática castellana. Anvers: En casa de Guillermo Simon. Edición facsimilar y estudio de C. García [1971]. Madrid: CSIC. 